\title{
B-chromosome selection in Allium schoenoprasum. I. Natural populations
}

\author{
D. S. Holmes* and \\ S. M. Bougourd $\dagger \ddagger$
}

\author{
* Department of Psychiatry, University College and \\ Middlesex School of Medicine, Wolfson Building, \\ Middlesex Hospital, Riding House Street, London \\ W1N 8AA, U.K. \\ $\dagger$ Department of Biology, University of York, York, \\ YO1 5DD, U.K.
}

The B-chromosome constitution of a seed sample of Allium schoenoprasum collected from a sub-population at the River Wye, Powys, S. Wales in July 1982 has been compared with that of a seedling sample collected from the same sub-population in September 1982. The seedling sample contained significantly more B-containing plants than the seed sample (64.1 per cent vs. 55.2 per cent), and the mean number of B-chromosomes in B-containing plants was also significantly increased in the seedlings $(2.44 \mathrm{vs}$. $2 \cdot 23)$. This implies that there is differential selection in favour of B-containing seedlings and seedlings with increased numbers of B-chromosomes during the initial stages of the life cycle when levels of mortality of $A$. schoenoprasum in this riverside habitat are high.

Non-standard types of B-chromosome accounted for a smaller proportion of the B-chromosomes in the seedlings compared with that in the seeds ( 9.7 per cent vs. 15.2 per cent), and there was a marked reduction in the frequency of plants carrying only non-standard B-types amongst the seedlings (6-2 per cent vs. $12 \cdot 5$ per cent).

\section{INTRODUCTION}

The occurrence of non-essential B-chromosomes with efficient accumulation systems within the genomes of many eukaryotic species has led to the widespread belief that they may be "selfish" rather than adaptive in evolutionary terms (Jones, 1985). There is little doubt that the accumulation of Bchromosomes, brought about by their nonMendelian inheritance, may in some cases be sufficient to counteract their often deleterious effects on fitness and fertility, and thus generate a stable polymorphism within a population. In some species, however, individuals carrying B-chromosomes appear to have superior fitness under conditions of stress (Rees and Hutchinson, 1973; Hutchinson, 1975). Such evidence argues against the view that B-chromosomes are maintained in populations solely as a direct result of accumulation mechanisms and supports the idea that natural selection may sometimes be a significant factor in the spread and maintenance of B-chromosomes.

In Allium schoenoprasum L. (chives), plants containing B-chromosomes have been found in

‡) whom correspondence should be addressed. populations along the banks of the River Wye, Powys (Bougourd and Parker, 1975). The Bchromosomes are apparently limited to populations at the downstream end of the plant's distribution where the frequency of B-containing plants reaches 65 per cent (Bougourd and Parker, 1979a). In general, the B-chromosomes are stable at mitosis and, although their numbers are enhanced in the anthers of some individuals and meiotic pairing behaviour is variable, there is no evidence of $\mathrm{B}$ chromosome accumulation in the offspring of experimental crosses (Bougourd and Parker, $1979 b$ ). In addition, Bs have been shown to have deleterious effects on aspects of vigour and fertility, at least under ǵlasshouse conditions. Conditions in the wild, especially during the early stages of the life cycle, are much more rigorous than those in a glasshouse. Perhaps the most important feature of the riverside habitat is the dramatic fluctuation in water levels which can occur even over short periods of time; this is likely to be a significant factor, especially in the germination of seeds and establishment of young seeedlings. Clearly, studies of the effects of B-chromosomes under natural conditions are necessary to understand how Bchromosomes are maintained in populations of $A$. schoenoprasum at the River Wye. 
In this paper we report the results of studies carried out at the River Wye on the natural survival of B-containing seedlings during the crucial first few months of life, and an attempt is made to relate these to the environmental conditions which the plants encounter.

\section{MATERIALS AND METHODS}

A. schoenoprasum is a bulbous perennial herb which reproduces both asexually by the production of daughter bulbs from short rhizomes and also sexually through seed. Bulbs lie dormant over winter and produce new leaf growth in February or March. Flowering occurs usually in June and July, with up to sixty flowers arranged within a single umbel. Once pollinated, the flowers take 3-4 weeks to mature into ripe capsules. Each flower produces a maximum of six seeds and, at the River Wye, umbels produce an average of $44.9 \pm 5.3$ seeds (Holmes, 1986).

\section{(a) The study area}

A. schoenoprasum occurs along an $18 \mathrm{~km}$ stretch of the River Wye, Powys, South Wales (Grid Ref. SO 030524 to SO 124398). It grows only where the bedrock is exposed, and clumps of bulbs are usually found firmly embedded in the rock crevices. Suitable stretches can extend up to several hundred metres along the river bank and are interspersed by stretches of unsuitable terrain, so clear delineation of populations is possible. Gene flow between populations is probably limited (Holmes, 1986).

In most years, the river level is consistently high from about October until March, and the plants are under water throughout this period. In some years, the river remains high from September until April; for example, in 1980/81, low lying plants were under water for 220 consecutive days (Holmes, 1986). In contrast, during the summer months, the river level is usually low and much of the bedrock is exposed. Since there is little soil in the rock crevices to retain moisture, conditions of drought prevail. Daily river levels recorded at Erwood Bridge (Grid Ref. SO 089438) throughout 1982 are shown in fig 1; these are similar to the levels at the experimental site.

The experiment was carried out along a $95 \mathrm{~m}$ stretch of the west bank of the River Wye (Grid Ref. SO 086439) where there was a discrete and easily recognisable sub-population with clearly defined boundaries. The species is relatively abundant in this area and in adult plants the B-chromosome frequency had previously been shown to be high (site Bii, 62 per cent B-containing plants, Bougourd and Parker, 1979b). The approximate level of the plants relative to the river levels throughout 1982 is shown on fig. 1 .

\section{(b) The seed sample}

In June 1982 the number of umbels present in the study area was estimated to be about 16,500 . Approximately 2000 umbels were collected at random in late July after flowering was complete. These were allowed to dry and the viable seed was collected. Two thousand seeds were sown in petri dishes on moist filter paper, and maintained under conditions previously found to be optimal for germination $\left(25^{\circ} \mathrm{C}, 16\right.$ hours light $) .99 \cdot 9$ per cent of the seeds germinated, and the seedlings were pricked out into Levington Universal compost. Only one seedling died. These plants constituted the seed sample.

\section{(c) The seedling sample}

In September 1982 the number of seeedlings present in the study area was estimated to be about

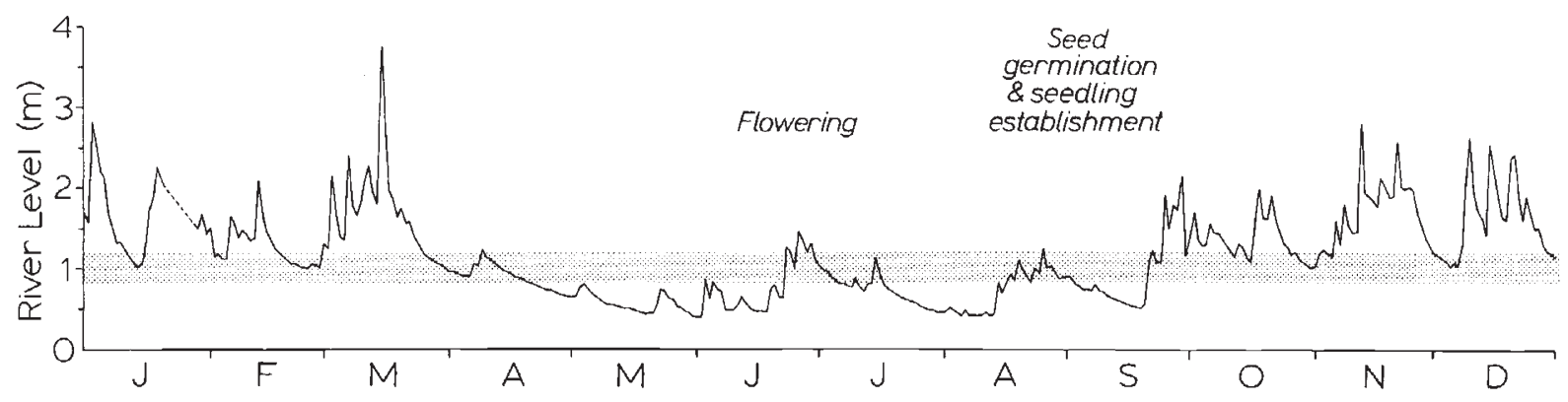

Figure 1 Daily river levels recorded by the Welsh Water Authority at Erwood Bridge throughout 1982. The approximate level of A. schoenoprasum relative to the river levels is shown by the hatched band, and the approximate times of flowering, seed germination and seedling establishment are indicated. 
23,500. Approximately 2000 seedlings were collected at random and transferred immediately into seed trays of Levington Universal compost. After 6 weeks, 1000 of these seedlings were chosen at random for potting on into $6 \mathrm{~cm}$ square pots, again in Levington Universal compost. None of the seedlings died after collection. These plants constituted the seedling sample.

\section{(d) Cytological methods}

The chromosome constitutions of 1000 seeds, chosen at random from the seed sample, and 1000 seedlings were determined at mitotic metaphase. Root tips were pre-treated in 0.05 per cent colchicine for $2 \mathrm{~h}$, fixed in $1: 3$ acetic alcohol and stained by the Feulgen method.

\section{RESULTS}

B-chromosome constitutions of the seed and seedling samples are summarised in tables 1 and 2 , and frequency distributions of non-B and B-containing individuals in the two samples are illustrated in fig. 2.

The proportion of plants in the seedling sample that contained B-chromosomes was $64 \cdot 1$ per cent compared with only 55.2 per cent of the seed

Table 1 Distribution of B-chromosome number in the Seed and Seedling samples

\begin{tabular}{lcc}
\hline B-number & Seeds & Seedlings \\
\hline 0 & 448 & 359 \\
1 & 231 & 222 \\
2 & 152 & 179 \\
3 & 70 & 104 \\
4 & 44 & 73 \\
5 & 24 & 30 \\
6 & 21 & 19 \\
7 & 8 & 6 \\
8 & 1 & 3 \\
9 & 0 & 3 \\
10 & 0 & 0 \\
11 & 0 & 1 \\
12 & 0 & 1 \\
Totals & 999 & 1000 \\
\hline
\end{tabular}

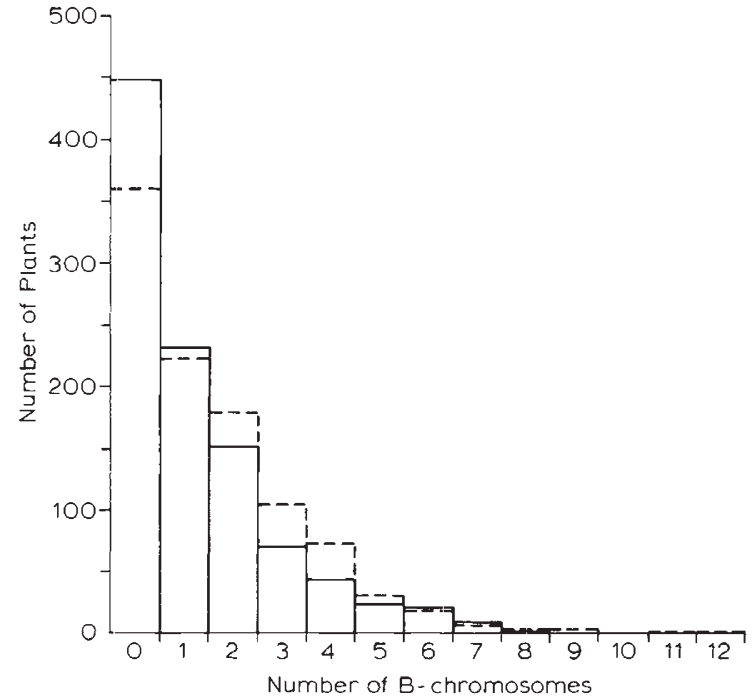

Figure 2 Frequency distributions of non-B and B-containing individuals in the seed and seedling samples. - Seed sample, - - Seedling sample.

sample; this represents a highly significant increase between the seed and seedling stages (contingency $\left.\chi_{(1)}^{2}=16.61, P<0.001\right)$. The number of B-chromosomes per plant varied from 0 up to 12 Bs in plants from the seedling sample and from 0 up to $8 \mathrm{Bs}$ in plants from the seed sample, although individual plants with more than 6 Bs were uncommon in both samples. The frequency distribution of Bclasses from 0 to 7 or more Bs was significantly different between the seed and seedling samples (contingency $\chi_{(7)}^{2}=27.88, P<0.001$ ), although there was no formal significance if the $O B$ class was excluded (contingency $\chi_{(6)}^{2}=11 \cdot 34, P>0 \cdot 05$ ). Overall, the mean number of B-chromosomes was 1.56 per plant for the seedlings and 1.23 per plant for the seeds, a highly significant increase in the seedlings $(d=4 \cdot 72, P<0.001)$. When only the Bcontaining individuals were taken into account, the mean number of Bs was still just significantly higher in the seedling sample, 2.44 compared with $2 \cdot 23(d=2 \cdot 42, P<0 \cdot 05)$.

Eight different types of B-chromosome were recorded in the seed and seedling samples (table

Table 2 Summary of the B-chromosome constitutions of the Seed and Seedling samples

\begin{tabular}{lccl}
\hline & Seeds & Seedlings & Comparison \\
\hline Percentage of B-containing plants & $55 \cdot 2$ & $64 \cdot 1$ & $\chi_{(\mathrm{1})}^{2}=16 \cdot 61, P<0 \cdot 001$ \\
Mean B per plant & $1 \cdot 23$ & $1 \cdot 56$ & $d=4 \cdot 72, P<0 \cdot 001$ \\
Mean B per B-containing plant & $2 \cdot 23$ & $2 \cdot 44$ & $d=2 \cdot 42, P<0 \cdot 05$ \\
Percentage of non-standard B-types & $15 \cdot 2$ & $9 \cdot 7$ & $X_{(1)}^{2}=19 \cdot 86, P<0 \cdot 001$ \\
Percentage of plants with only non-standard Bs & $12 \cdot 5$ & $6 \cdot 2$ & $X_{(1)}^{2}=14 \cdot 06, P<0 \cdot 001$ \\
\hline
\end{tabular}


Table 3 B-chromosome types in the Seed and Seedling samples

\begin{tabular}{lrr}
\hline B-type & Seeds & Seedlings \\
\hline $\mathrm{B}^{1-1}$ & 1044 & 1413 \\
$\mathrm{~B}^{\mathrm{t}-2}$ & 101 & 58 \\
$\mathrm{~B}^{\mathrm{t}-3}$ & 7 & 20 \\
$\mathrm{~B}^{\mathrm{t}-4}$ & 2 & 8 \\
$\mathrm{~B}^{\mathrm{t}-5}$ & 1 & 0 \\
$\mathrm{~B}^{\mathrm{m}-1}$ & 71 & 63 \\
$\mathrm{~B}^{\mathrm{m}-2}$ & 3 & 1 \\
$\mathrm{~B}^{\mathrm{sm}-1}$ & 2 & 1 \\
Totals & 1231 & 1564 \\
\hline
\end{tabular}

3). All but one, a relatively large telocentric Bchromosome of approximately $2.8 \mu \mathrm{m}$ in length designated $\mathrm{B}^{\mathrm{t}-5}$, have been described previously (Bougourd and Parker, 1975; Bougourd and Parker, 1979b). The most frequent B-type in both samples was the standard $\mathrm{B}^{\mathrm{t}-1}$, but non-standard B-types accounted for a smaller proportion of the B-chromosomes in the seedlings, 9.7 per cent compared with $15 \cdot 2$ per cent (contingency $\chi_{(1)}^{2}=19 \cdot 86$, $P<0.001)$. There was a marked reduction in the frequency of plants amongst the seedlings carrying only non-standard B-types rather than only standard or standard together with non-standard Bs (table 4; contingency $\chi_{(1)}^{2}=14.06, P<0.001$ ).

Table 4 Numbers of B-containing plants containing only standard Bs, a mixture of standard and non-standard Bs, or non-standard Bs only, in the Seed and Seedling samples

\begin{tabular}{|c|c|c|c|c|}
\hline Type of plant & Seeds & & Seed & ngs \\
\hline Standard Bs only & $436\}$ & \multirow{2}{*}{$87 \cdot 5 \%$} & 535 & \multirow{2}{*}{$93 \cdot 8 \%$} \\
\hline $\begin{array}{l}\text { Standard plus } \\
\text { non-standard Bs }\end{array}$ & $46\}$ & & $66\}$ & \\
\hline Non-standard Bs only & 69 & $12 \cdot 5 \%$ & 40 & $6 \cdot 2 \%$ \\
\hline Totals & \multicolumn{2}{|l|}{551} & \multicolumn{2}{|l|}{641} \\
\hline
\end{tabular}

\section{DISCUSSION}

The data clearly show that a marked change in B-chromosome constitution occurs between the seed and seedling stages of the life cycle. The seedling sample collected in September 1982 contained about the same frequency of B-containing plants as the adult plants in the sample area $(64 \cdot 1$ per cent cf. 62 per cent, see Bougourd and Parker, $1979 a$ ), but significantly more B-containing plants than the seed sample collected from the same area the previous July $(64 \cdot 1$ per cent $\mathrm{cf} .55 \cdot 2$ per cent). The mean number of B-chromosomes in Bcontaining plants was also significantly increased in the seedlings. This implies that there is differential selection in favour of B-containing individuals and for individuals with increased numbers of B-chromosomes during the initial stages of the life cycle.

The loss of potential individuals from the population during this period is dramatic. The number of seedlings present in the study area in September was only about 3 per cent of the estimated number of seeds produced by the plants within that area, and this is not untypical of the levels of mortality which we have estimated in other years (Holmes, 1986). Such high levels of mortality are not surprising in this riverside habitat. Throughout the summer months, conditions of drought prevail and seeds, once shed, lie dormant beneath the parent plant. Germination occurs only when sufficient moisture becomes available, possibly after a fall of rain or when the river begins to rise and localised pools of water fill the rock crevices. Following successful germination, the newly emerged seedlings must quickly become established in the rock crevices before the river floods in the autumn. Only deep anchorage in the crevices provides sufficient security under these conditions, and many of the seedlings, especially those which have germinated in the moist moss covering the rocks, have an insufficiently secure foothold and are washed away together with any remaining ungerminated seeds. Since our results show that B-containing individuals are more likely than individuals without Bs to survive until this stage under these conditions, we can conclude that B-chromosomes confer a selective advantage to survival during either seed germination or early seedling establishment, or both.

Similar examples in natural populations of a change in the incidence of $\mathrm{B}$-chromosomes during the life cycle have previously been reported. In Myrmeleotettix maculatus, Robinson and Hewitt (1976) reported a rise in B-chromosome frequency in the autumn eggs relative to the adult population, and a fall again in the spring eggs. However, reanalysis of these data, taking into account the inclusion of karyotypes of related eggs in an egg pod, suggested that there was only weak evidence of a rise in B-frequency between adults and autumn eggs and no change in frequency between autumn and spring eggs (see Shaw et al., 1985). In Rattus fuscipes, individuals from natural populations were karyotyped before and after breeding (Thomson, 1984). Rats with B-chromosomes were found to be at least twice as likely to be lost from the population before breeding than rats without B-chromosomes. In both of these examples, B-chromosome 
accumulation is thought to contribute significantly to the maintenance of the B-chromosomes in the populations.

In contrast, no evidence for accumulation of B-chromosomes has been found in $A$. schoenoprasum (Bougourd and Parker, 1979b). In experimental crosses there is usually a slight loss of Bs in the offspring, and it is probable that similar losses occur in the natural populations since the B-frequency in the seed sample was lower $(55.2$ per cent) than the frequency previously recorded for the adult population in the same area ( 62 per cent). Both the absence of an effective accumulation mechanism and the apparently deleterious effects of Bs on adult plants support the idea that selection at the early stages of the life cycle is important in maintaining B-chromosomes in populations of $A$. schoenoprasum at the River Wye.

Finally, it is of interest to compare the types of B-chromosome that occurred in the seed and seedling samples. Non-standard types of Bchromosome were significantly less frequent amongst the seedlings relative to the seeds. At least nine different non-standard B-types occur in $\boldsymbol{A}$. schoenoprasum at the River Wye and evidence from experimental crosses suggests that there is a dynamic system for their production (Bougourd and Parker, 1979b; Holmes, 1986). However, nonstandard Bs have a slightly higher frequency of mitotic instability than the standard Bs, and this may at least partly account for the loss of nonstandard B-chromosomes between the seed and seedling stages. In addition, the standard B is by far the most common type of B-chromosome in these populations and has presumably evolved over successive generations in response to the conditions at the River Wye. It is perhaps not surprising therefore, that the non-standard, possibly newly arisen B-types fare less well under these conditions than do their standard counterparts.
Acknowledgements We are very grateful to $\mathrm{Mr} \mathrm{J}$. H. Wilson for allowing us access to the study area at the River Wye and for the interest he has shown in our work, and to the Welsh Water Authority for providing us with data on river levels. We would also like to thank Dr T. J. Crawford for his invaluable statistical advice and helpful discussions. We gratefully acknowledge the award of a studentship from N.E.R.C. to D.S.H.

\section{REFERENCES}

BOUGOURD, S. M. AND PARKER, J. S. 1975. The B-chromosome system of Allium schoenoprasum I. B-distribution. Chromosoma (Berl), 53, 273-282.

BOUGOURD, S. M. AND PARKER, J. S. 1979a. The B-chromosome system of Allium schoenoprasum III. An abrupt change in B-frequency. Chromosoma (Berl), 75, 385-392.

BOUgourd, S. M. AND PARKER, J. S. 1979 b. The B-chromosome system of Allium schoenoprasum II. Stability, inheritance and phenotypic effects. Chromosoma (Berl), 75, 369383.

HOLMES, D. S. 1986. D.Phil Thesis, University of York.

HUTCHINSON, J. 1975. Selection of B chromosomes in Secale cereale and Lolium perenne. Heredity, 34, 39-52.

JONES, R. N. 1985. Are B chromosomes 'selfish'? In CavalierSmith, T. (ed.) The Evolution of Genome Size, J. Wiley \& Sons Ltd., pp. 397-425.

REES, H. AND HUTCHINSON, J. 1973. Nuclear DNA variation due to B chromosomes. Cold Spring Harbor Symp. Quant. Biol., 38, 175-182.

ROBINSON, P. M. AND HEWITT, G. M. 1976. Annual cycles in the incidence of B chromosomes in the grasshopper, $M y r$ meleotettix maculatus (Acrididae: Orthoptera). Heredity, 36, 399-412.

SHAW, M. W., HEWITT, G. M. AND ANDERSON, D. A. 1985. Polymorphism in the rates of meiotic drive acting on the B chromosome of Myrmeleotettix maculatus. Heredity, 55, 61-68

THOMSON, R. L. 1984. B chromosomes in Rattus fuscipes Il. The transmission of B chromosomes to offspring and population studies: support for the "parasitic" model. Heredity, $52,363-372$. 